\title{
Estimation of Anti-HBs Titer in Health Care Professionals of a Tertiary Care Centre of Southern Assam
}

\author{
Debadatta Dhar Chanda $^{1}$, Atanu Chakravarty ${ }^{2}$, Barnamoy Bhattacharjee ${ }^{3}$ \\ ${ }^{1}$ Associate Prof of Microbiology \& P.I VRDL, Silchar Medical College \& Hospital, Silchar-14, Assam \\ ${ }^{2}$ Assistant Professor of Microbiology, Silchar Medical College \& Hospital, Silchar, Assam \\ ${ }^{3}$ Post Graduate Trainee in M.D. Microbiology, Silchar Medical College \& Hospital, Silchar, Assam
}

Corresponding Author: Debadatta Dhar Chanda

\begin{abstract}
Background- Due to occupational exposure to blood, body fluids and sharps, the health care professionals are at increased risk of contracting the Hepatitis B virus infection than general population. To combat this, all the health care professionals must be immunized with protective level of anti-HBs but anti-HBs titer gradually wanes with passage of time and may be influenced by gender, smoking or chewing tobacco, diabetes mellitus etc. This study was thus carried out to find the percentage of health care professionals with protective titer of anti$\mathrm{HBs}$ and find the association (if any) of low anti-HBs titer and factors like gender, smoking, diabetes mellitus and time elapsed post vaccination.
\end{abstract}

Method- This cross-sectional study has been carried out with proper ethical clearance from May2018- September2019 in Serology section of VRDL under Department of Microbiology in a Medical College of Southern Assam on serum samples collected from 150 health care professionals vaccinated with 3 doses of recombinant $\mathrm{HBsAg}$ vaccine atleast 5years back. Anti-HBs IgG concentration was measured by conventional ELISA in multistandard mode.

Result- Out of 150 participants, 95 were males and 55 were females. 27 participants smoked/ chewed tobacco, 8 had diabetes mellitus. Booster dose was received by 23. Protective level of anti-HBs IgG (>10 IU/ml) was found in $66 \%(98 / 150)$ of HCP only. Low anti-HBs titer has been found to be significantly associated with Diabetes mellitus $(p-0.03)$ and passage of more than 10 years post primary vaccination ( $p$ 0.005 ) but no significant association has been found with gender, smoking and history of blood transfusion.

Conclusion- HBsAg vaccine doesn't impart everlasting protection. So, all HCP, especially those with co-morbidities should get their antiHBs titer estimated after vaccination to check out for adequate seroconversion and attainment of protective titer. If found inadequate, they should go for repeat vaccination /booster doses.

Key Words- Healthcare professionals, Vaccinated, Anti HBs IgG, Assam

\section{INTRODUCTION}

According to the World health Organization (WHO) approximately 240 million people are chronically infected with malady of HBV infection and more than $7,80,000$ die every year due to its wide spectrum consequences [1]. India is considered to have intermediate level of HBV endemicity with a prevalence rate of $2-8 \%{ }^{[2]}$. The number of HBsAg carriers in India has been estimated to be over 50 million. Every year, one million Indians are at risk for HBV and about 1,00,000 die from HBV infection ${ }^{[3]}$. Due to occupational exposure to blood, body fluids and sharps, the health care professionals are at 2-4 times increased risk of contracting the Hepatitis B virus infection than general population ${ }^{[4]}$. Throughout the world, millions of healthcare professionals work in health 
institutions and it is estimated that 600,000 to 800,000 cut and puncture injuries occur among them per year, of which approximately $50 \%$ are not registered. The annual proportion of health-care workers exposed to blood-borne pathogens was $5.9 \%$ for $\mathrm{HBV}$, corresponding to about 66,000 HBV infections in health-care workers worldwide ${ }^{[5]}$. In developing regions, $40 \%$ $65 \%$ of $\mathrm{HBV}$ infections in health-care workers occurred due to per-cutaneous occupational exposure. In contrast, the fraction of HBV was less than $10 \%$, in developed regions, largely because of immunization and post-exposure prophylaxis ${ }^{[5]}$. Although most of the HBV infections in healthcare workers are attributed to per-cutaneous exposure, in many studies, most infected HCWs could not recall any overt per-cutaneous injury ${ }^{[6]}$. In addition, HBV has been demonstrated to survive in dried blood, at room temperature, on environmental surfaces, for at least one week. Thus, HBV infections that occur in HCWs with no history of exposure might have resulted from direct or indirect blood or body fluid exposures that inoculated HBV into the mucosal surfaces or cutaneous scratches and other lesions ${ }^{[7]}$ contains the highest HBV titers of all body fluids and is the most important vehicle of transmission in the healthcare settings. HBsAg is also found in several other body fluids, including breast milk, bile, cerebrospinal fluid, feces, nasopharyngeal washings, saliva, semen, sweat, and synovial fluid. However, most body fluids are not efficient vehicles of transmission because they contain low quantities of infectious $\mathrm{HBV}$, despite the presence of HBsAg ${ }^{[8]}$. Therefore, avoiding occupational blood exposure is the primary preventive means for the transmission of HBV. To combat the high risk of HBV infection among HCWs, routine preexposure vaccination of $\mathrm{HCWs}$ against Hepatitis B and the use of universal precautions to prevent exposure to blood and potentially infectious body fluids have been recommended in many countries as the main stay of prevention ${ }^{[9]}$. The risk of HBV in an unvaccinated person after a single episode of needle prick injury ranges from 6 $-30 \%{ }^{[10]}$ and even $0.00001 \mathrm{ml}$ of blood can transmit HBV. Reports from India indicate that only $16-60 \%$ of HCWs have received complete HBV immunization. Paramedics have a higher risk of $\mathrm{HBV} / \mathrm{HCV}$ transmission and receive HBV vaccination less often than doctors ${ }^{[11]}$.

Hepatitis B vaccine provides protection against infection with HBV by producing immunity or antibodies to the surface protein or outer coat of the virus.

Recently, third generation vaccines produced in mammalian Chinese Hamster Ovary $(\mathrm{CHO})$ cells ${ }^{[12]}$ have been shown to induce an immune response, which occurs earlier and is stronger. Even in many so called "non-responders" to $\mathrm{S}$ protein a protective immune response was induced.

Anti-HBs estimation after vaccination is recommended for healthcare workers and public safety workers at high risk for continued percutaneous or mucosal exposure to blood or body fluids to guide post-exposure prophylaxis, chronic haemodialysis patients, HIV-infected persons, sex partners of HBs Ag-positive persons and other immune compromised persons and for follow-up [13]. Testing should be performed 1 month after administration of the last dose of the vaccine series using a method that allows determination of a protective concentration of anti-HBs.

\section{PURPOSE OF THE STUDY}

1. To find the percentage of health care professionals in a tertiary health care centre with protective titer of anti-HBs

2. To find the association (if any) of low anti-HBs titer and factors like gender, smoking, diabetes mellitus and time elapsed post vaccination.

\section{MATERIALS \& METHODS}

This prospective cross-sectional study was carried out from May 2018September 2019 in Serology section of the Viral Research Diagnostic Laboratory under 
Department of Microbiology, in a tertiary care hospital of Southern Assam after obtaining Ethical clearance from the Institutional ethical Committee. Blood samples were collected after obtaining written consent from total 150 vaccinated health care workers in the age group of 2465years (Inclusion-criteria-Health Care Professionals vaccinated with 3 doses of recombinant Hepatitis B vaccine at least 5 years back) in Clot activator vials and serum samples were preserved at $-20^{\circ} \mathrm{C}$ until tested. Subsequently these serum samples were thawed and Anti-HBs IgG concentration was measured by conventional ELISA using HBsAb ELISA kit from Diapro Diagnostics Italy (CE-IVD approved). Quantitative ELISA was done in multistandard mode of ROBONIK ELISA reader using microwells plate coated with inactivated Hepatitis B surface antigens. Samples are pre-treated in the well with a specimen diluent able to block interference present in vaccinated individuals. In $1^{\text {st }} 1$ hour of incubation, the IgG antibodies are captured onto the coated wells at $37^{\circ} \mathrm{C}$. After washing, during the $2^{\text {nd }}$ hour of incubation the captured antibodies are detected by an HBsAg, labelled with peroxidase (HRP), that specifically binds the second available binding site of these antibodies. The enzyme specifically bound to wells, by acting on the substrate /chromogen mixture, generates an optical signal that is proportional to the amount of $\mathrm{HBsAb}$ in the sample and can be detected by an ELISA reader.
The amount of antibodies may be quantitated by means of a standard curve calibrated against the W.H.O reference preparation. Primary and secondary filters used are $450 \mathrm{~nm}$ and $620 \mathrm{~nm}$ respectively.

\section{STATISTICAL ANALYSIS-}

Statistical analysis of result and calculation for $\mathrm{p}$ value by obtaining chi square score was done by using online $p$ value calculator from Statistical Package for the Social Sciences (SPSS) version 26. Association of factors with $\mathrm{P}$ value $<0.05$ has been considered significant.

\section{RESULT}

Out of 150 participants, 95 were males and 55 were females. Designation wise 37 were senior faculties, 41 were Junior Residents, 30 were Interns, 19 were nursing staffs and 23 were Lab technicians. 27 participants habitually smoked/chewed tobacco, 8 had diabetes mellitus. Booster dose was received by 23 . Protective level of anti-HBs $\operatorname{IgG}(>10$ $\mathrm{IU} / \mathrm{ml})$ was found in $66 \%(98 / 150)$ of $\mathrm{HCP}$ only. Based on peak concentration of antiHBs, the vaccine recipients have been categorized into following 3 groups ${ }^{[14]}$ -

1. Non-responders with peak anti-HBs concentration $<10 \mathrm{IU} / \mathrm{L}$

2. Low responders with peak anti-HBs concentration of 10-100 IU/L

3. Good responders with peak anti-HBs concentration > $100 \mathrm{IU} / \mathrm{L}$

\begin{tabular}{|l|l|}
\hline $\begin{array}{l}\text { ANTI-HBs IgG } \\
\text { TITER }\end{array}$ & $\begin{array}{l}\text { NO. Of HEALTH CARE } \\
\text { PROFESSIONALS }\end{array}$ \\
\hline$<10 \mathrm{IU} / \mathrm{mL}$ & 51 \\
\hline $10-100 \mathrm{IU} / \mathrm{mL}$ & 40 \\
\hline $100-500 \mathrm{IU} / \mathrm{mL}$ & 59 \\
\hline
\end{tabular}

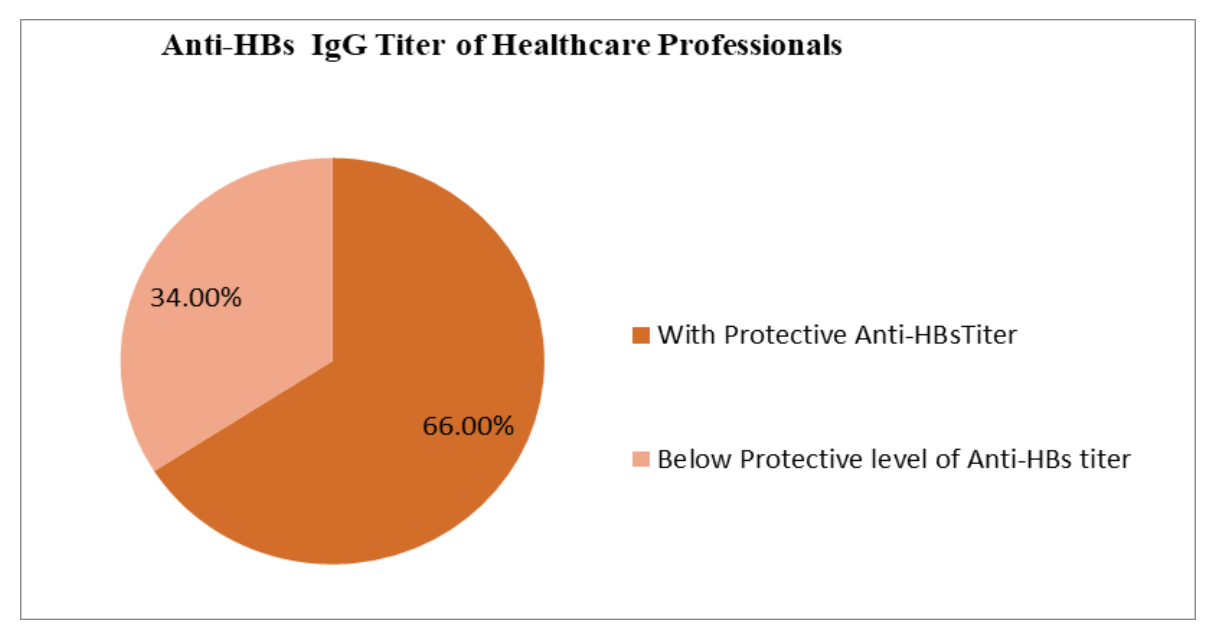




\begin{tabular}{|l|l|l|}
\hline GENDER & $\begin{array}{l}\text { BELOW } \\
\text { PROTECTIVE } \\
\text { ANTIHBS IgG TITER }\end{array}$ & $\begin{array}{l}\text { PROTECTIVE } \\
\text { ANTI-HBs } \\
\text { TITER }\end{array}$ \\
\hline MALE & 34 & 61 \\
\hline FEMALE & 18 & 37 \\
\hline
\end{tabular}

\section{OBSERVATION}

Gender predilection of health care professionals has not been found to significantly associated with low anti-HBs titer $(p-0.704)$. Below protective anti-HBs titer has been found to be significantly associated with Diabetes mellitus $(p-0.03)$ and passage of more than 10 years post primary vaccination $(p-0.005)$ but no significant association has been found with habit of smoking or chewing tobacco and history of blood transfusion.

\section{DISCUSSION}

In this study conducted in the only tertiary health care centre of Southern Assam, $66 \%$ of the completely vaccinated healthcare professionals have been found to have protective anti-HBs titer. Similar estimate of protective antibody titer $(67.92 \%)$ was found by Syed Rahamathulla et $a^{[15]}$ in a cross-sectional study carried out among 106 vaccinated doctors in Andhra Pradesh. Lakshmanan et al ${ }^{[14]}$ from Agartala have found protective anti-HBs titer in $89 \%$ of the healthcare professionals, while Dr. V K Kataria et al ${ }^{[16]}$ from New Delhi found that only $46.16 \%$ of the vaccinated healthcare professionals had protective antibody levels after 10years post HBsAg vaccination. Sarman Singh et al ${ }^{[8]}$ in a study conducted on vaccinated healthcare professionals of AIIMS New Delhi found that $79 \%$ of them had protective antiboby titer (>10IU/L). Studies carried out in South Indian states like that of T.V Rao et al ${ }^{[17]}$ from Thrissur Kerala, Shruti Hegde et al ${ }^{[18]}$ from Mangalore Karnataka and Reshmi Gopalkrishnan et al [9] from Calicut Kerala found protective anti-HBs titer in $89 \%, 92 \%$ and $100 \%$ of the completely vaccinated healthcare professionals respectively.

Presence of Diabetes mellitus in participating health care professionals has been significantly attributed to inadequate level of antiHBs IgG in this study. This finding has been seconded by Lakshmanan et $\mathrm{al}^{[14]}$ in their study conducted in Agartala Govt. Medical College.

Unlike the study of Shruti Hegde et al ${ }^{[18]}$ in dental students of Mangalore and that of Syed Rahamathulla et al ${ }^{[15]}$ in vaccinated doctors in Andhra Pradesh where male gender has been attributed to low antiHBs titer, no such statistically significant gender predilection has been found with low anti HBs IgG in our study

Anti-HBs IgG titer has been said to wane with time elapsed after vaccination and so has been found in our study where passage of $>10$ years post vaccination has been found to have been significantly associated with inadequate protective antiHBs. Similar observation has been made in the study of Dr V K Kataria et al ${ }^{[16]}$ in their study on healthcare professionals from New Delhi.

The fact observed in this study that Smoking of tobacco is not significantly associated with low level of anti-HBs IgG has been in discordance with studies of Shruti Hegde et al ${ }^{[18]}$ from Karnataka in South India and Lakshmanan et al ${ }^{[14]}$ from Agartala in North east India as they have found smoking to be a significant attribute for low levels of anti-HBs IgG titer in medical students and health care workers respectively.

Though conducted in non-health care professional, Study by Amy B Middleman et al ${ }^{[19]}$ in 420 subjects in the age group 16-19 years found that only $24 \%$ had protective anti-HBs titer after 5 years of vaccination but they did check the anamnestic response to find that the nonresponders also developed protective antiHBs titer after receiving a booster dose of the vaccine, proving that immune memory against recombinant $\mathrm{HBsAg}$ was intact leading to rapid rise in antibody response. This finding is at par with the views and opinions stated in the study of Lakshmanan et al ${ }^{[14]}$ from Agartala that persistence of immunological memory remains intact for at least 10years. Thus, it reiterates the need 
and enhancing role of booster dose of HBsAg vaccine

\section{CONCLUSION}

As this study brings to light that $34 \%$ of the completely vaccinated healthcare professionals of this tertiary care hospital lack protective anti-HBs titer, health care professionals must bear in mind that merely completing the primary schedule of recombinant HBsAg vaccination against Hepatitis-B doesn't impart them everlasting protection. So, they all, especially those with co-morbidities like Diabetes Mellitus should get their anti-HBs titer estimated 1 month after vaccination and follow up at intervals to check out adequate priming of immune system leading to seroconversion and attainment of protective titer. In order to verify the persistence and intactness of immune memory, anti-HBs titer should be estimated at least 5 years after completing the primary schedule if not done after one month of completing the primary vaccination schedule and if antiHBs titer is found inadequate they should go for repeat vaccination or administration of booster doses. This study also calls for raising awareness and scaling up of complete HBsAg vaccination in healthcare professionals of tertiary care hospitals.

\section{ACKNOWLEDGEMENT}

We express our gratitude to VRDL of our Medical College under DHR-ICMR. We are thankful to all the health care professionals for participating in this institutional study.

\section{Limitation}

Involvement of the incompletely vaccinated or the recently vaccinated (at least 6 months back) health care professionals could have projected the exact scenario of seroconversion to protective IgG level. This study also could not follow up the non-responders to post booster dose anti-HBs IgG estimation to check out for the persistence of Immunological memory.

\section{Conflict of Interest: None}

Source of Funding: VRDL, Silchar Medical College

\section{Ethical Approval: Approved}

\section{REFERENCES}

1. World Health Organization, Fact sheets. "Hepatitis B," 2014 http://www.who.int/mediacentre/factsheets/f s204/en/.

2. National Centre for Disease Control (NCDC). Quarterly Newsletter 2014; 3(1).

3. Centers for Disease Control and Prevention. Hepatitis B information for health professionals: hepatitis B FAQs for health professionals.

4. Annapurna G.Sajjan, Smita S.Mangalgi. Awareness and practice of complete hepatitis B vaccination and anti-Hbs testing in vaccinated health care workers. JKIMCU, Vol.4, No.2, April-June 2015, 81 ISSN 2231-4261.

5. Prüss-Üstün A, Rapiti E, Hutin Y (2005) Estimation of the global burden of disease from sharps injuries to health-care workers. Am J Ind Med 48: 482-490.

6. US Public Health Service (2001) Updated U.S. Public Health Service Guidelines for the Occupational Exposures of $\mathrm{HBV}, \mathrm{HCV}$, and HIV and Recommendations for Postexposure Prophylaxis. MMWR Recomm Rep 50: 1-52.

7. Werner BG, Grady GF (1982) Accidental hepatitis-B-surface-antigen-

positiveinoculations: Use of $\mathrm{e}$ antigen to estimate infectivity. Ann Intern Med 97: 367-369.

8. Singhal V, Bora D, Singh S (2011) Prevalence of Hepatitis B Virus Infection in Healthcare Workers of a Tertiary Care Centre in India and Their Vaccination Status. J Vaccines Vaccin 2:118. doi:10.4172/2157-7560.1000118

9. Reshmi Gopalakrishnan and Srinath Ramamurthy. 2017. Seroprevalence of Hepatitis B Infection among Health Care Workers and the Importance of Anti HBs Testing among the Health Care Workers. Int.J.Curr.Microbiol.App.Sci. 6(10): 22802285.doi: https://doi.org/10.20546/ijcmas.2017.610.27 0 
10. Yen $\mathrm{YH}$, Chen $\mathrm{CH}$, Wang $\mathrm{JH}$, Lee $\mathrm{CM}$, Changchien CS, Lu SN. (2005) Liver Int. 25: 1162-1168.

11. Sukriti, Pati NT, Sethi A, et al. Low level of awareness, vaccine coverage, and the need for booster among health care workers in tertiary care hospitals in India. $J$ Gastroenterol Hepatol 2008; 23:1710-1715.

12. Hourvitz A, Mosseri R, Solomon A, et al. Reactogenicity and immunogenicity of a new recombinant hepatitis $B$ vaccine containing PreS antigens: a preliminary report. J Viral Hepat 1996;3(1):37-42.

13. Advisory Committee on Immunization Practices, Centers for Disease Control and Prevention (CDC). Immunization of HealthCare Personnel. Recommendations of the ACIP. MMWR 2011;60(7):1-45.

14. Lakshmanan KP, Bhaumik P, Sarkar P et al. Study of immunization status by estimation of anti-HBs antibody in post hepatitis B vaccinated individuals.J. Evid. Based Med. Healthc. 2017; 4(79), 4656-4660. DOI:10.18410/jebmh/2017/931.

15. Sathish Kumar Akkim, Rahamathulla Syed, Manimaran Manickam, Sufia Sulatana, Mamatha.D.M, Estimation of anti-hbs antibody titre level in vaccinated Indian Doctors, IJCSME- SCSMB-16-March2016; ISSN-2349-8439

16. B.S .Mahawal, Dr.N.Bhai, Dr.V.K.Kataria, N.Gulati, Dr.I.Chandola; Estimation of Anti
Hbs antibody titer in adults during 5-10 years period following three doses of vaccine; IOSR Journal of Pharmacy and Biological Sciences (IOSR-JPBS)e-ISSN: 2278-3008, p-ISSN:2319-7676. Volume 7, Issue 1 (Jul. - Aug. 2013), PP 20-23

17. Rao T V, Suseela I J, Sathiavathy K A. Estimation of antibodies to HBsAg in vaccinated health care workers. Indian $\mathrm{J}$ Med Microbiol 2008; 26:93-94

18. Shruthi Hegde, Praveen B.N., Sumona Pal, Shishir Ram Shetty, Vidya Ajila, Subhas Babu \& Harini K, Serum antibody analysis following hepatitis $\mathrm{B}$ vaccination for occupational risk assessment among dental students, NUJHS Vol. 4, No.1, March 2014, ISSN 2249-7110

19. Amy B Middleman et al Duration of protection after infant hepatitis B vaccination series. Pediatrics. 2014 Jun; 133(6):e1500-7. doi: 10.1542/peds. 20132940.

How to cite this article: Chanda DD, Chakravarty A, Bhattacharjee B et.al. Estimation of anti-HBs titer in health care professionals of a tertiary care centre of Southern Assam. International Journal of Research and Review. 2021; 8(8): 510-515. DOI: https://doi.org/10.52403/ijrr.20210869 